\title{
Ultrasonography guided supraclavicular brachial plexus block for excision of multiple calcinosis cutis in CREST syndrome: a safe approach
}

\author{
Jui Yeshavant Lagoo ${ }^{1 *}$, Bindu George $e^{2}$ \\ Assistant Professor ${ }^{1}$, Associate Professor ${ }^{2}$, Department of Anaesthesia, \\ St John's Medical College Hospital, Bangalore, India.
}

*Corresponding author: geetjui@gmail.com

\begin{abstract}
CREST syndrome is a subset of systemic sclerosis, a multi systemic connective tissue disorder with an autoimmune aetiology. The cardinal features are calcinosis cutis, Raynaud's phenomenon, oesophageal dysfunction, sclerodactyly and telangectasia. The pathophysiology involves widespread vascular damage and microangiopathic vascular obliteration. It has anaesthetic considerations like difficult airway,reflux oesophagitis, pulmonary aspiration, interstitial lung disease, Raynaud's phenomenon, cardiomyopathy and difficult venous access. There are very few reports in literature detailing anaesthetic implications. We report successful management of a patient with CREST syndrome posted for excision of calcinosis cutis under ultrasonography (USG) guided supraclavicular brachial plexus block.
\end{abstract}

Key words: CREST syndrome; USG guidance; supraclavicular block

\section{Introduction}

CREST syndrome is a subset of systemic sclerosis accounting for $20-25 \%$ of cases with an incidence of 9-19 per million with a predilection for females in child bearing age and African race. ${ }^{1}$ This multisystemic disease has an impact on every aspect of anaesthetic management but currently there are no standardised guidelines.

\section{Case Report}

A 60 year old female, a known case of CREST syndrome with calcinosis, telangectasia and sclerodactyly presented for excision of multiple subcutaneous nodules on right arm. Medical history revealed skin thickening, increased photosensitivity, Raynaud's phenomenon without oesophageal regurgitation. Airway evaluation revealed limited neck extension, microstomia, mouth opening of two fingers and a difficult airway was anticipated. Routine investigations, echocardiogram and pulmonary function tests were normal.

Preoperatively alprazolam $0.25 \mathrm{mg}$, pantoprazole $40 \mathrm{mg}$ and metoclopramide $10 \mathrm{mg}$ were administered orally. Venous access was difficult and was secured with $22 \mathrm{G}$ cannula. Right brachial plexus block by supraclavicular approach was performed under USG guidance with $12 \mathrm{ml} 0.5 \%$ bupivacaine. Sensory and motor blockade were adequate. Bony prominences were protected. Normothermia was ensured with warm intravenous fluids and blanket. The position of pulse oximeter probe and noninvasive blood pressure (NIBP)cuff was changed at regular intervals along with monitoring of skin discoloration.

\section{Discussion}

CREST syndrome is an acronym for calcinosis cutis, Raynaud's phenomenon, oesophageal dysfunction, sclerodactyly and telangiectasia. It is a subset of systemic sclerosis associated with overproduction and deposition of collagen, glycosaminoglycans and fibronectins within connective tissue of skin and internal organs. It has an autoimmune aetiology associated with anti-centromere antibodies. The systemic involvement takes a form of microangiopathic vascular obliteration and progressive fibrosis involving oesophagus 90\%, skin 90\%, Raynaud's phenomenon $99 \%$, lungs $35 \%$, heart $9 \%$, myopathy $11 \%$ and renal crisis $2 \% .{ }^{1,2}$

Difficult airway is frequently encountered due to microstomia, restricted mouth opening, atrophied nasal alae, fibrosis of temperomandibular joint and tightening of skin over face and neck causing restricted neck extension. Careful airway manipulation is mandatory to prevent bleeding from mucosal telangiectasiae. $^{2,3,4,5}$ In our case, regional anaesthesia avoided all these difficulties. 
A major anaesthetic consideration is oesophageal dysmotility with increased risk of pulmonary aspiration. Thus administration of proton pump inhibitor, $\mathrm{H}_{2}$ blocker and prokinetic drugs is recommended. ${ }^{2,3,4}$ Sellick's manoeuvre may be ineffective due to fibrosis of the oesophagus and may result in catastrophe during rapid sequence induction.

Repeated aspiration and pulmonary infiltration leading to interstitial and peri-bronchial fibrosis and pulmonary arterial hypertension resulting in cor-pulmonale contribute to pulmonary morbidity and protective lung strategies need to be employed. This is minimized by avoiding general anaesthesia. ${ }^{2,3}$

Difficulties in venous access and blood pressure monitoring are encountered due to chronic vasoconstriction, skin thickening and flexion contractures. Arterial cannulation can be technically difficult and precipitate Raynaud's phenomenon. ${ }^{2,3,5}$

Careful positioning is preferably done with the cooperation of an awake patient. Bony prominences and pressure areas need to be adequately protected. Scarring of eyelids, and inadequate closure require lubrication of eyes. ${ }^{2,3}$

Raynaud's phenomenon ranges from vascular hyperactivity to complete obstruction triggered by exposure to cold, vibration and emotional stress resulting in ischaemia, necrosis and ulceration of the peripheries. ${ }^{1,2,3,5}$ This mandates a close attention to strict temperature control with wrapping of limbs, infusion of warm fluids, anxiolysis and periodic change of the site of pulse oximeter probe and NIBP cuff. ${ }^{3,5}$

Cardiac involvement can manifest rarely as myocardial fibrosis, cardiomyopathy, conduction defects and arrhythmias. Contracted intravascular volume may cause severe hypotension during induction. Involvement of skeletal muscles may result in unpredictable response to neuromuscular blockers. ${ }^{2,3}$

Regional anaesthesia can serve as a safe alternative to general anaesthesia. It offers several advantages like improved tissue perfusion, prevention of Raynaud's, better wound healing and control of severe and opioid resistant pain. ${ }^{2,3,6}$

USG guidance aids in minimizing technical difficulties, reducing performance time, reducing number of needle punctures, avoiding intraneural injection and improves accuracy, safety and success rate. A definitive and unique advantage demonstrated with USG guidance is a reduction in the dose of local anaesthetic required to block nerves allowing more than one regional block to be performed simultaneously., 8,10

But the role of regional anaesthesia may be limited by technical challenges like positioning difficulties and altered fascial planes. Altered sensation may result in intraneural injection. Abnormal nerve conduction may interfere with nerve stimulator technique. A prolonged sensory blockade with an unpredictable spread of local anaesthetics has been observed. Injection of local anaesthetic can cause compression, vascular and neurological compromise.,

\section{Conclusion}

Anaesthetist has an integral role in care of these high risk patients. Knowledge about pathophysiology, careful preoperative evaluation, advocating USG guided regional anaesthesia result in safe anaesthesia conduct.

\section{References}

1. Varga J. Systemic sclerosis and related disorders. In: Fauci A, Braunwald E, Kapser D, Hauser S, Longo D, Jameson L, Loscalzo J, editors. Harrison's principles of internal medicine. $\mathrm{Vol}$ 2; 17th ed; New York: McGraw Hill Medical; 2008:2096-105

2. Schwatrz JJ. Skin and musculoskeletal diseases. In: Hines RL, Marschall KE, editors. Paul AK, adapting editor. Stoelting's Anesthesia and coexisting disease. 5th ed; New Delhi :Elsevier; 2010:486-7

3. Dempsey ZS, Rowell S, McRobert R. The role of regional and neuraxial anesthesia in patients with systemic sclerosis. Local and Regional Anesthesia 2011;4:47-56 PMid:22915893 PMCid:PMC3417973

4. Erol DD. Thoracic epidural blockade in an elderly with achalasia due to scleroderma for thoracotomy, oesophagealmyotomy and cystotomy - capitonnage. The Internet $J$ Anaesthesiology2006;11(1).

5. Roberts JG, Sabar R, Gianoli JA, Kaye AD. Progressive systemic scleroderma - clinical manifestations and anaesthetic considerations. $J$ ClinAnesth 2002;14(6):474-81 http://dx.doi.org/10.1016/S0952-8180(02)00380$\underline{\mathrm{X}}$

6. Garcia-Sanchez MJ, Galdo-Abadin JR, PalacioRodriguez MA, Prieto-Cuellar M. Anaesthetic 
management of a pregnant patient with CREST syndrome. Int J ObsAnesth1999;8(2):146-7

7. Sulemanji DS, Donmez A, Arslan G. Epidural anaesthesia for laparoscopic cholecystectomy in a patient with scleroderma. $\mathrm{Br} J$ Anaesth 2006;97(5):749

http://dx.doi.org/10.1093/bja/ael260

PMid: 17032668

8. Wadhwa A, Kandadai SK, Tongpresert S et al. Ultrasound guidance for deep peripheral nerve blocks - a brief review. Anesthesiol Res Practvol 2011(2011), Article ID 262070.
DOI:10.1155/2011/262070.

PMCid:PMC3145343. PMid:21808644

9. Koscielniak-Nielsen ZJ. Ultrasound guided peripheral nerve blocks: what are benefits? ActaAnaesthScand 2008;52(6):727-37

http://dx.doi.org/10.1111/j.13996576.2008.01666.x

PMid: 18477070

10. Sandhu NS, Manne JS, Medabalmi PK, Capan LM. Sonographically guided infraclavicular brachial plexus block in adults. $J$ Ultrasound Med 2006;25:1555-61

PMid: 17121950 